\title{
Bruceloma hepático. Manifestación infrecuente de una enfermedad endémica
}

\section{Hepatic Brucelloma. Uncommon Manifestation of an Endemic Disease}

\author{
Andrés Domínguez ${ }^{1}$ Carolina Navarro ${ }^{1}$ Esteban Zirulnik ${ }^{1}$ Maximiliano Noceti ${ }^{1}$ \\ 1 Servicio de Diagnóstico por Imágenes, Clínica de Cuyo, Mendoza, \\ Argentina \\ Address for correspondence Andrés Domínguez, PhD, Servicio de \\ Diagnóstico por Imágenes, Clínica de Cuyo, Av. José Vicente Zapata \\ 63, Mendoza, Argentina (e-mail: andresdominguez82@gmail.com).
}

Rev Argent Radiol 2020;84:36-38.

Estimados editores:

La brucelosis es la zoonosis más frecuente en el mundo, con aproximadamente 500.000 nuevos casos reportados anualmente. $^{1}$ Presenta afinidad por el sistema reticuloendotelial y suele cursar con afectación difusa del parénquima hepático, siendo el bruceloma una manifestación infrecuente, que ocurre en aproximadamente el $1 \%$ de los pacientes. $^{2}$

Se presenta el caso de un varón de 44 años de edad, que consultó por fiebre de origen desconocido de dos semanas de evolución. El laboratorio reveló un aumento de enzimas hepáticas e incremento en los reactantes de fase aguda. La fórmula leucocitaria se encontraba dentro de los normales. Con esos hallazgos se solicitó un ultrasonido, que reveló la presencia de una imagen hipoecoica de comportamiento expansivo en el segmento lateral del lóbulo hepático izquierdo. Se decidió avanzar en la caracterización mediante resonancia magnética (RM) de abdomen, donde se observó una imagen expansiva predominantemente sólida con un área central líquida. El componente sólido se mostraba levemente hipointenso en imagen ponderada en $\mathrm{T} 1$, con realce arterial en las series post contraste y persistencia del realce en los cortes tardíos, observándose además un fino halo periférico que mostraba captación progresiva del medio de contraste, probablemente por fibrosis (-Fig. 1). El área central líquida se mostraba hiperintensa en imagen ponderada en T2 y DWI, con caída de la señal en el mapa ADC, atribuible a contenido purulento (-Fig. 2).

Como antecedente relevante, el paciente refirió que convivía con un perro encontrado en la calle desde aproximadamente un mes antes de comenzar con los síntomas, hecho que resultaría clave en la resolución del

received

April 23, 2018

accepted

October 8, 2019
DOI https://doi.org/

10.1055/s-0039-3399549.

ISSN 1852-9992. caso. Con esos hallazgos, se planteó la posibilidad de un absceso hepático versus un tumor abscedado, debido al gran componente sólido de la lesión.

Se decidió colocar un drenaje externo con guía tomográfica con el propósito de descartar una zoonosis vinculada al contacto reciente, extrayéndose material purulento. Los cultivos revelaron la presencia del microorganismo Brucella Canis. Se realizó esquema de antibioticoterapia específica con adecuada respuesta al cabo de dos meses de tratamiento, observándose en la RM de control una imagen con aspecto secuelar ( - Fig. 3 ).

La brucelosis es una infección granulomatosa crónica generada por un cocobacilo gram-negativo, que puede comprometer a seres humanos por diferentes vías, que tienen en común la afectación de animales domésticos que sirven de reservorio: una de ellas es la ingestión de alimentos contaminados, habitualmente leche o sus derivados no pasteurizados (especialmente Brucella Mellitensis). Otra es por vía inhalatoria, la cual tiende a presentarse con mayor frecuencia en los meses de primavera/verano (periodo de reproducción) y por último, por contacto directo con secreciones de un animal infectado (semen, sangre, orina, heces, etc.). ${ }^{3}$

El sitio de compromiso más frecuente es el sistema osteoarticular, siendo el bruceloma hepático una manifestación extremadamente infrecuente, que se presume vinculada a la infección persistente de los macrófagos, causando una necrosis caseosa del tejido granulomatoso. ${ }^{4}$

El aspecto imagenológico es el de una lesión pseudotumoral, habitualmente cavitada, que presenta típicamente una calcificación central, ese último hallazgo ausente en nuestro caso. ${ }^{4,5}$

Copyright (c) 2020, Sociedad Argentina de Radiología. Publicado por Thieme Revinter Publicações Ltda., Rio de Janeiro, Brazil. Todos los derechos reservados.
License terms

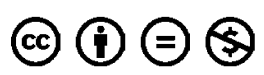



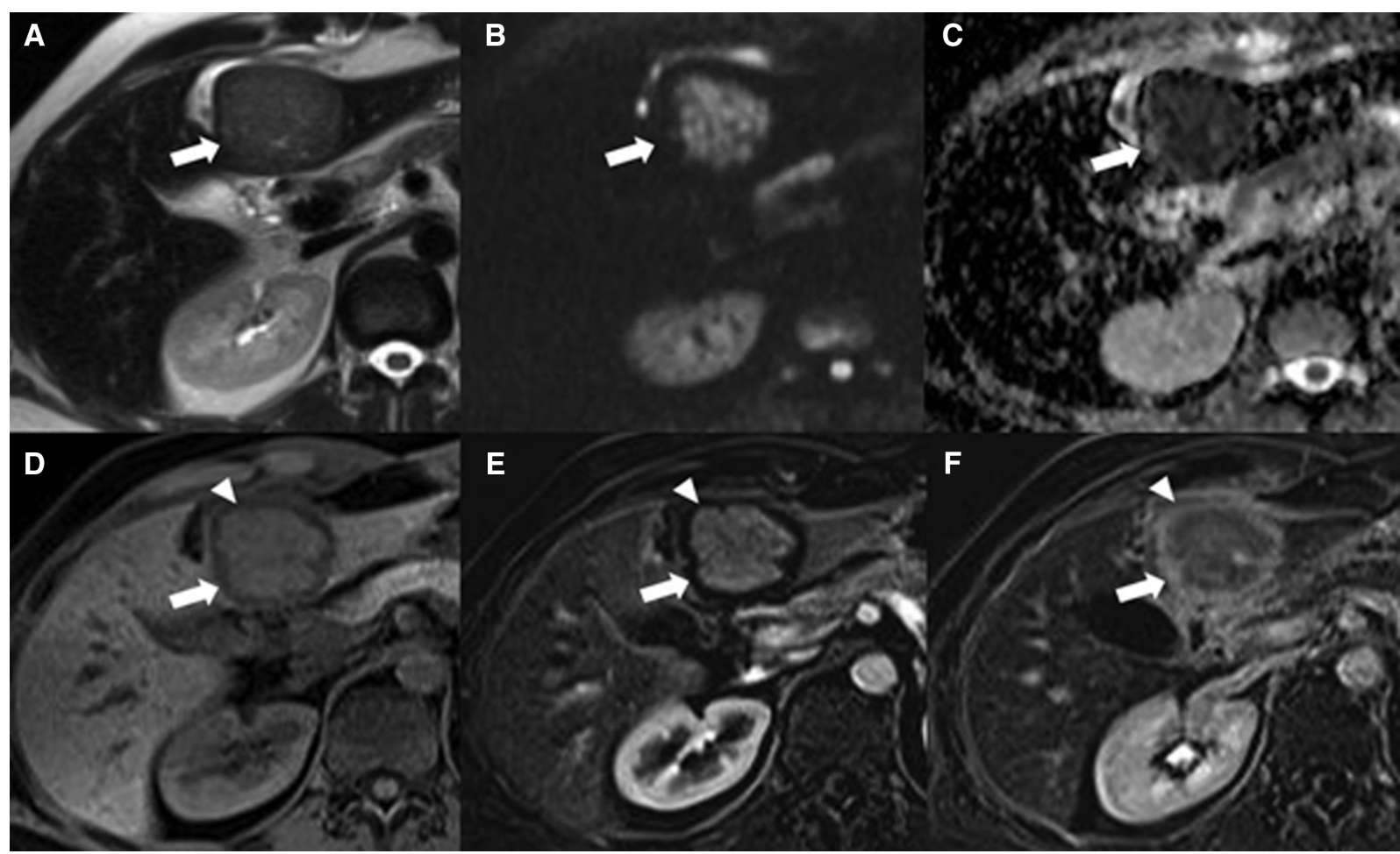

Fig. 1 Cortes axiales de RM que muestran una masa en el segmento lateral (flechas), con señal levemente hiperintensa tanto en las imágenes ponderadas en T2, como en los valores altos de b de la difusión, mostrando caída de la señal en el mapa ADC (A, B y C). En los cortes ponderados en T1 fat sat se muestra levemente hipointensa (D), con realce durante la fase arterial del contraste endovenoso, donde se observa además un halo periférico hipointenso (cabezas de flecha), que muestra captación del material de contraste durante la fase de equilibrio (E y F).

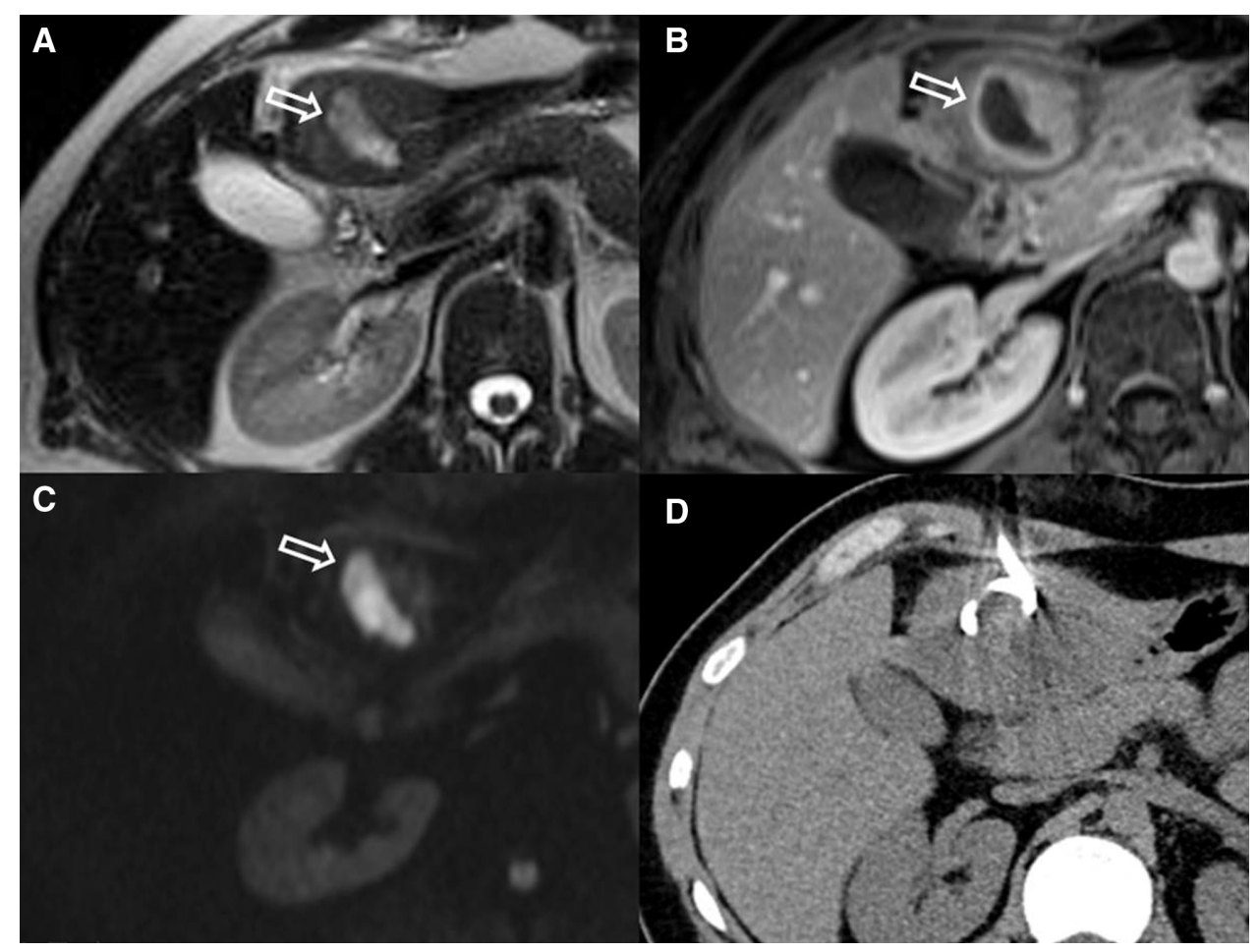

Fig. 2 Continuación: La masa muestra, en su sector inferior, un centro líquido con señal hiperintensa en la imagen ponderada en T2, sin realce en las series post contraste y con franca restricción en la difusión (flechas), atribuible a contenido purulento (A, B y C). Corte axial de tomografía computada (TC) que muestra un drenaje percutáneo en el interior de la colección (D). 


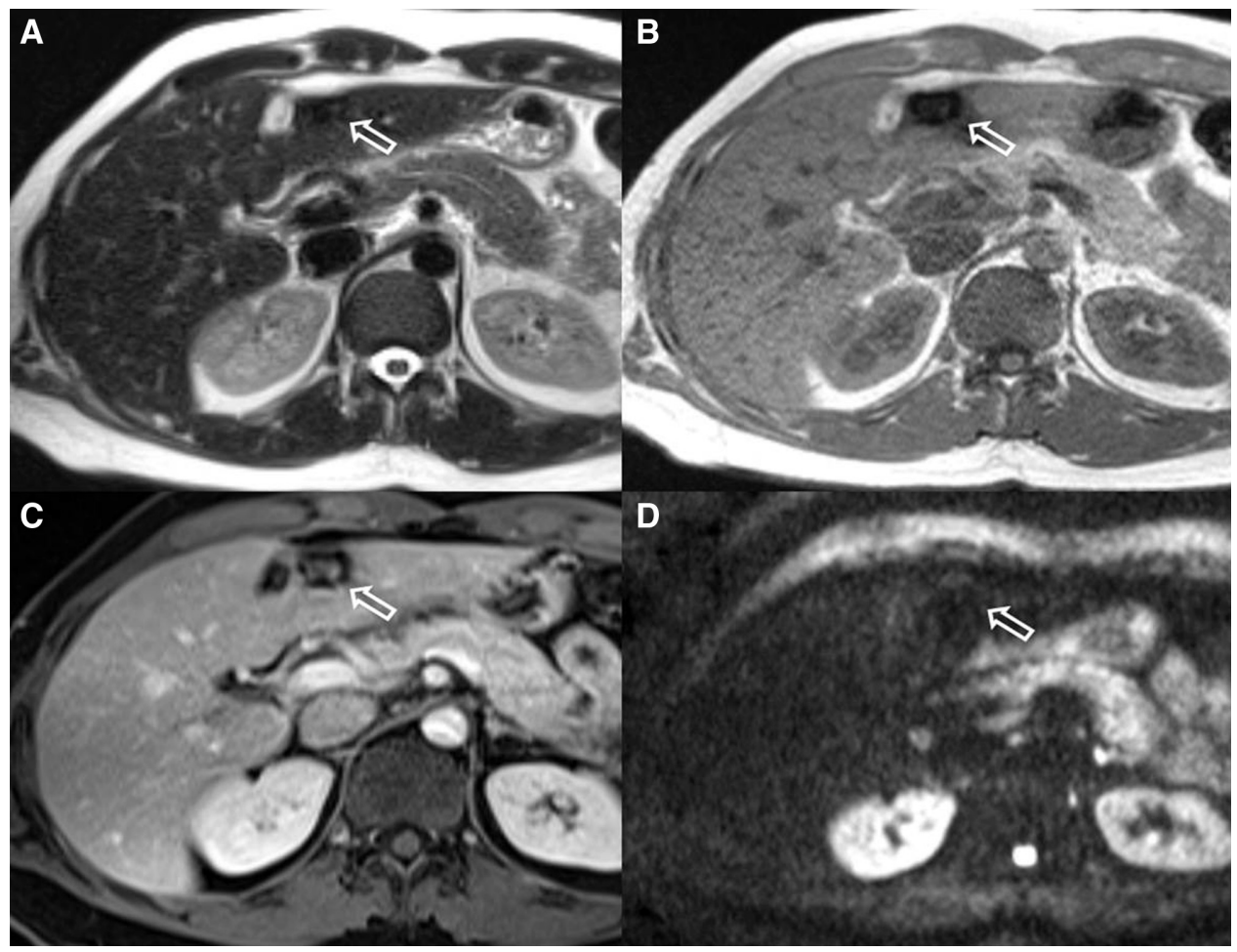

Fig. 3 RM de control ocho semanas después de comenzado el esquema de antibioticoterapia específico, donde se observa una pequeña imagen secuelar (flechas), hipointensa en las imágenes ponderadas en T2 y T1 (A y B), sin realce post contraste (C) y sin restricción en la difusión (D).

El método de diagnóstico más específico consiste en el aislamiento bacteriológico del germen, aunque cabe aclarar que su eficacia es baja (principalmente en fases crónicas), por lo que cultivos negativos no descartan en forma definitiva la enfermedad. En esos casos, los métodos serológicos son de elección (ELISA, técnicas de aglutinación, técnicas de fijación del complemento, etc.). ${ }^{6}$

El tratamiento se basa en antibioticoterapia específica, siendo el esquema más utilizado la combinación de doxiciclina más rifampicina por un periodo de seis semanas, mientras que la opción quirúrgica es una posibilidad a considerar con el propósito de evitar la recurrencia. ${ }^{7}$

En un contexto clínico-epidemiológico favorable, es necesario tener en cuenta la brucelosis entre los diagnósticos diferenciales de una masa con centro cavitado a nivel hepático, más aún cuando se acompaña de una calcificación central. Su diagnóstico precoz y un tratamiento oportuno contribuyen a evitar recaídas y la progresión hacia la cronicidad.

Confidencialidad de los Datos

El autor declara que ha seguido los protocolos de su centro de trabajo sobre la publicación de datos de pacientes y que todos los pacientes incluidos en el estudio han recibido información suficiente y han dado su consentimiento informado por escrito para participar en dicho estudio.
Conflicto de Intereses

Los autores del trabajo declaran no tener ningún conflicto de intereses.

\section{Bibliografía}

1 Pappas G, Papadimitriou P, Akritidis N, Christou L, Tsianos EV. The new global map of human brucellosis. Lancet Infect Dis. 2006;6 (02):91-99

2 Ariza J, Pigrau C, Cañas C, Marrón A, Martínez F, Almirante B, et al. Current understanding and management of chronic hepatosplenic suppurative brucellosis. Clin Infect Dis. 2001;32(07):1024-1033

3 Guerra H. The brucellae and their success as pathogens. Crit Rev Microbiol. 2007;33(04):325-331

4 Sisteron O, Souci J, Chevallier P, Cua E, Bruneton JN. Hepatic abscess caused by Brucella US, CT and MRI findings: case report and review of the literature. Clin Imaging. 2002;26(06): 414-417

5 Rovery C, Rolain JM, Raoult D, Brouqui P. Shell vial culture as a tool for isolation of Brucella melitensis in chronic hepatic abscess. J Clin Microbiol. 2003;41(09):4460-4461. Doi: 10.1128/JCM.41.9.44604461.2003

6 Lucero Nidia E, Ayala Sandra M, Escobar Gabriela I, Jacob Néstor R. The Value of Serologic Tests for Diagnosis and Follow up of Patients having Brucellosis. Am J Infect Dis. 2007;3(01):27-35

7 Skalsky K, Yahav D, Bishara J, Pitlik S, Leibovici L, Paul M. Treatment of human brucellosis: systematic review and metaanalysis of randomised controlled trials. BMJ. 2008;336 (7646):701-704 